\title{
Computational studies of NMDA receptors: differential effects of neuronal activity on efficacy of competitive and noncompetitive antagonists
}

This article was published in the following Dove Press journal:

Open Access Bioinformatics

20 August 2010

Number of times this article has been viewed

\author{
Nicolas Ambert ${ }^{1}$ \\ Renaud Greget ${ }^{1,2}$ \\ Olivier Haeberlé \\ Serge Bischoff' \\ Theodore W Berger ${ }^{3,4}$ \\ Jean-Marie Bouteiller ${ }^{3,4}$ \\ Michel Baudry 3,4 \\ 'Rhenovia Pharma, Mulhouse, France; \\ 2MIPS, Mulhouse, France; ${ }^{3}$ Neuroscience \\ Program, ${ }^{4}$ Department of Biomedical \\ Engineering and Center for Neural \\ Engineering, University of Southern \\ California, Los Angeles, CA, USA
}

Correspondence: Michel Baudry HNB534, 364I Watt Way, USC, Los Angeles, CA 90089-2520, USA

Tel +12137409188

Fax + I 2137405687

Email baudry@usc.edu

\begin{abstract}
N-methyl-D-aspartate receptors (NMDARs) play important physiological as well as pathological roles in the central nervous system (CNS). While NMDAR competitive antagonists, such as D-2-amino-5-phosphopentanoic acid (AP5) have been shown to impair learning and memory, the noncompetitive antagonist, memantine, is paradoxically beneficial in mild to moderate Alzheimer's disease (AD) patients. It has been proposed that differences in kinetic properties could account for antagonist functional differences. Here we present a new elaborated kinetic model of NMDARs that incorporates binding sites for the agonist (glutamate) and coagonist (glycine), channel blockers, such as memantine and magnesium $\left(\mathrm{Mg}^{2+}\right)$, as well as competitive antagonists. We first validated and optimized the parameters used in the model by comparing simulated results with a wide range of experimental data from the literature. We then evaluated the effects of stimulation frequency and membrane potential $(\mathrm{Vm})$ on the characteristics of AP5 and memantine inhibition of NMDARs. Our results indicated that the inhibitory effects of AP5 were not strongly affected by $\mathrm{Vm}$, but decreased with increasing stimulation frequency. In contrast, memantine inhibitory effects decreased with both increasing Vm and stimulation frequency. They support the idea that memantine could provide tonic blockade of NMDARs under basal stimulation conditions without blocking their activation during learning. Moreover they underline the necessity of considering receptor kinetics and the value of the biosimulation approach to better understand mechanisms of drug action and to identify new ways of regulating receptor function.
\end{abstract}

Keywords: kinetic model, stimulation frequency, memantine, AP5, biosimulation, systems neurobiology

\section{Introduction}

$\mathrm{N}$-methyl-D-aspartate receptors (NMDARs) are ionotropic glutamate receptors involved in numerous physiological (synaptic plasticity, developmental plasticity, learning, and memory) and pathological (excitotoxicity, neurodegeneration) processes in the central nervous system (CNS). ${ }^{1,2}$ Two particular characteristics are critical for the wide range of functions regulated by these receptors: the voltage-dependency of the gating of the NMDAR channel and its calcium $\left(\mathrm{Ca}^{2+}\right)$ permeability. Functional NMDARs are tetrameric receptors generally composed of two NR1 subunits and two of the four NR2 (NR2A-NR2D) subunits although the discovery of NR3 subunits has increased the complexity of NMDAR family. ${ }^{3,4}$ The nature of NR2 subunit(s) strongly influences receptor properties, including agonist affinity, deactivation kinetics, singlechannel conductance, $\mathrm{Ca}^{2+}$ permeability, and channel blockade by magnesium $\left(\mathrm{Mg}^{2+}\right) .{ }^{3,5}$ NMDAR activation requires the binding of glycine (on NR1 subunit) and glutamate 
(on NR2 subunit) and is regulated by a number of small molecules, such as polyamines (ie, spermine), which bind at different allosteric sites of both types of subunits. $\mathrm{Mg}^{2+}$ binding to the NMDAR channel provides its voltage-dependency. ${ }^{6}$ Several antagonists have been developed and have been widely used to better understand the role of NMDARs in both physiological and pathological conditions. In particular, D-2amino-5-phosphopentanoic acid (AP5) has been shown to competitively block the receptor while the activity-dependent channel blocker MK-801 represents an example of a noncompetitive blocker. ${ }^{7,8}$

More recently, another noncompetitive blocker, memantine, has been identified, and is now widely used for the treatment of Alzheimer's disease (AD). Because of the known role of NMDARs in synaptic plasticity and in learning and memory, the precise mechanism of action of memantine as an anti-AD treatment has been debated. ${ }^{9,10}$ In particular, it has been proposed that memantine acts as a weak, voltagedependent channel blocker, which would produce a tonic blockade of the channel at resting membrane potential, therefore explaining its neuroprotective effects. On the other hand, memantine would not be effective during trains of high frequency stimulation, thereby limiting the risks of negative effects on learning and memory.

To gain a better insight into the functioning of NMDARs and the mechanisms of action of drugs such as memantine and to test various hypotheses regarding differences between competitive and noncompetitive NMDARs blockers, we developed a kinetic model of the NR1/2A type of NMDARs, as it is the key NMDAR involved in long term potentiation (LTP) of synaptic transmission. ${ }^{6,11,12}$ The model was first optimized by comparison of simulated results with a variety of experimental data reported by several laboratories. Secondly, we used this model to analyze the effects of frequency of stimulation and membrane potential (Vm) on AP5 and memantine-mediated inhibition of NMDAR current. The results indicate that the inhibitory effects of AP5 are independent of $\mathrm{Vm}$ but decrease with increased stimulation frequency, whereas the inhibitory effects of memantine decrease with both increasing stimulation frequency and $\mathrm{Vm}$. Thus, our results validate the hypothesis that memantine could exert neuroprotective effects by blocking the receptors under basal stimulation conditions, while leaving intact the role of NMDARs in memory-related processes. They underscore the importance of variation in neuronal activity in determining the functional characteristics of a variety of molecules acting on NMDARs. Finally, the results indicate that the simulation approach represents a powerful tool to analyze, in great detail, the intimate mechanisms of compounds acting on NMDARs and to optimize the quest for more efficacious drugs. ${ }^{13}$

\section{Methods NMDAR kinetic scheme}

We implemented the kinetic scheme of the NMDAR previously published by Schorge et $\mathrm{al}^{11}$ using graphical user interface-based design tools for visual model development such as Narrator (http://www.narrator-tool.org/), JDesigner (http://sbw.kgi.edu/), and CellDesigner (http://www. celldesigner.org/), as shown in Figure 1. NMDAR (R) binds two glutamate molecules (glu) and two glycine molecules (gly) to generate state R_2Glu_2Gly. Double-liganded NMDAR can then enter in state 5 and state 6 (conformational change) and proceed toward states: Open1 (via state 4), Open2 (via state 5) and Desensitized (via state 6). The open probability for NMDAR (Popen) was calculated as a sum of probabilities for states Open1 plus Open2. In the present study, except when otherwise indicated, binding sites for the coagonist glycine were always fully occupied, as all simulations were performed in the continuous presence of a saturating concentration of glycine.

\section{Model reactions and simulations}

The dynamics of the kinetic scheme were described by a set of deterministic ordinary differential equations (ODEs) in a SBML (Systems Biology Markup Language) file, which is a standard format for investigation of the dynamic behavior of biological systems. ${ }^{14}$ The values for the different parameters indicated in Figure 1 are shown in Table 1. Differential equations were numerically solved using a solver.

The computer used to run simulations was a Dell Inspiron 1720 laptop PC (Intel Core 2 Duo, $2.5 \mathrm{GHz}$ ) with 4GB RAM.

\section{Model of NMDAR-mediated current}

Channel conductance of NMDAR was set to 40 picosiemens (pS) for the lowest conductance state (state Open1) and $247 \mathrm{pS}$ for the highest conductance state (state Open2). The reversal potential for NMDA current $\left(\mathrm{I}_{N M D A}\right.$ ) was set at -0.7 millivolts $(\mathrm{mV}) \mathrm{I}_{N M D A}$ was then calculated using the following equations: ${ }^{15}$

$$
I_{N M D A}=n b_{N M D A} \frac{I_{0}}{1+\frac{\left[M g^{2+}\right]_{0}}{K_{0}} e^{-\delta z F \psi_{m} / R T}}
$$




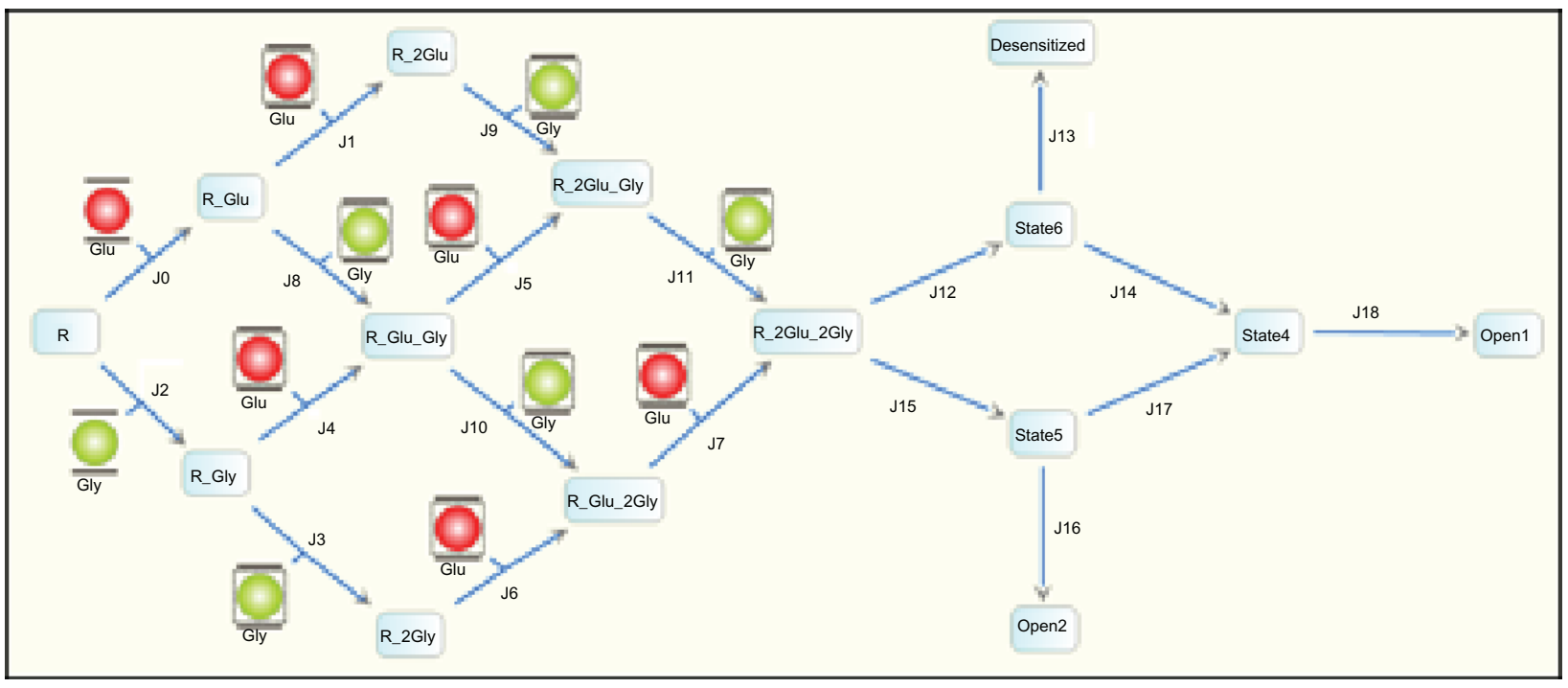

Figure I Kinetic scheme of the NMDA receptor. Representation of the kinetic scheme proposed by Schorge et al" implemented in a graphical user interface-based design tool for visual model development. The rate constants indicated in the schema are provided in Table I.

$$
g=g_{1}+\frac{g_{2}-g_{1}}{1+e^{a \psi_{m}}} ; I_{0}=g\left(V-V_{r e v}\right) O(t) ; I_{N M D A}^{C a^{2+}}=P_{f} I_{N M D A}
$$

where $O(\mathrm{t})$ is the open probability for $N M D A$ channel; $g$, the conductance $(\mathrm{pS}) ; \psi_{m}$, the holding membrane potential $(\mathrm{mV}) ; V_{r e v}$, the reversal potential (set at $-0.7 \mathrm{mV}$ ); $\mathrm{Mg}^{2+}$, the magnesium concentration in the external solution; $K_{0}$, the half maximal inhibitory concentration $\left(\mathrm{IC}_{50}\right)$ of $\mathrm{Mg}^{2+}$ at $0 \mathrm{mV}$ (equal to $1 \mathrm{mM}$ ); $\delta$, the electrical distance of the magnesium binding site from the outside of the membrane (set at 0.8 ); $\mathrm{z}$, the calcium valence ( set at +2 ); $\mathrm{R}$, the molar gas constant

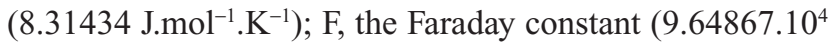
C.mol $\left.{ }^{-1}\right) ; \mathrm{T}$, the absolute temperature $\left(273.15^{\circ} \mathrm{K}\right) ; g_{1}$, the conductance of state Open1 (set at $40 \mathrm{pS}$ ); $g_{2}$, the conductance of state Open2 (set at $247 \mathrm{pS}$ ); $\alpha$, the steepness of the voltage-dependent transition from $g_{1}$ to $g_{2}$ (set at 0.01 ); $n b_{N M D A}$, the number of NMDARs in one dendritic spine; and

Table I Values of kinetic parameters for the NMDAR model from Schorge et al $^{\prime \prime}$

\begin{tabular}{|c|c|c|c|}
\hline Parameters $^{\mathbf{a}}$ & Agonist & $\mathbf{k}_{\text {on }}$ & $\mathbf{k}_{\text {off }}$ \\
\hline $\mathrm{J} 0, \mathrm{~J} 4$ and $\mathrm{J} 6$ & Glutamate & $2^{\mathrm{a}} 8.3 \mathrm{mM}^{-1} \cdot \mathrm{ms}^{-1}$ & $0.0263 \mathrm{~ms}^{-1}$ \\
\hline $\mathrm{JI}, \mathrm{J} 5$ and J7 & Glutamate & $\cdot 8.3 \mathrm{mM}^{-1} \cdot \mathrm{ms}^{-1}$ & $2^{\mathrm{a}} 0.0263 \mathrm{~ms}^{-1}$ \\
\hline $\mathrm{J} 2$, J8, and $\mathrm{J} 9$ & Glycine & $2^{\mathrm{a}} 10 \mathrm{mM}^{-1} \cdot \mathrm{ms}^{-1}$ & $0.0291 \mathrm{~ms}^{-1}$ \\
\hline J3,JIO and & Glycine & $10 \mathrm{mM}^{-1} \cdot \mathrm{ms}^{-1}$ & $2^{\mathrm{a}} 0.0291 \mathrm{~ms}^{-1}$ \\
\hline $\mathrm{J} 12$ and $\mathrm{J} 17$ & & $0.0671 \mathrm{~ms}^{-1}$ & $0.15 \mathrm{~ms}^{-1}$ \\
\hline $\mathrm{Jl} 3^{\mathrm{b}}$ & & $0.92 \mathrm{I} / 0.03 \mathrm{~ms}^{-1}$ & I. $13 / 9.5 \mathrm{e}^{-4} \mathrm{~ms}^{-1}$ \\
\hline $\mathrm{Jl} 4$ and $\mathrm{JI} 5$ & & $2.03 \mathrm{~ms}^{-1}$ & $22.8 \mathrm{~ms}^{-1}$ \\
\hline J16 & & $0.787 \mathrm{~ms}^{-1}$ & $11.2 \mathrm{~ms}^{-1}$ \\
\hline J18 & & $35.2 \mathrm{~ms}^{-1}$ & $0.728 \mathrm{~ms}^{-1}$ \\
\hline
\end{tabular}

Notes: a Equivalent transition types are numbered according to the kinetic scheme depicted in Figure I. ' Original/optimized parameters.
$P_{f}$, their permeability to calcium (set at $5 \%$ of total ionic permeability).

\section{Results \\ Model validations}

For validation experiments, the conditions used in the simulation ( $\mathrm{Vm}, \mathrm{Mg}^{2+}$ concentration, glycine concentration, stimulation protocol, glutamate concentration, etc) are indicated in the text and/or figure legends for each experiment. Importantly, these parameters were set at values similar to those used in the experimental conditions and therefore varied from experiment to experiment. Our choice of experiments was guided by a number of criteria, including well-described experimental conditions and output measures that we could calculate in the simulation. For simulations comparing the effects of Vm and stimulation frequency on the inhibitory effects of AP5 and memantine, we used identical stimulation protocols, which are described in the text.

Using the kinetic scheme from Figure 1, we first determined the time course of NMDAR activation in response to short (1 or 2 milliseconds [ms]) and long (10 ms) applications of glutamate, based on previous studies by Schorge et al ${ }^{11}$ and Wyllie et al. ${ }^{16}$ The kinetic parameters values are shown in Table 1. Simulated values for open probability of NMDAR channels (Figure 2A) were calculated after a delay of $10 \mathrm{~ms}$, in response to a $2 \mathrm{~ms}$ pulse of $1 \mathrm{mM}$ glutamate in the presence of glycine $(20 \mu \mathrm{M})$ at $\mathrm{Vm}$ of $-80 \mathrm{mV}$. The maximum predicted open probability was 0.256 and was reached $21 \mathrm{~ms}$ following glutamate application; the open probability time 

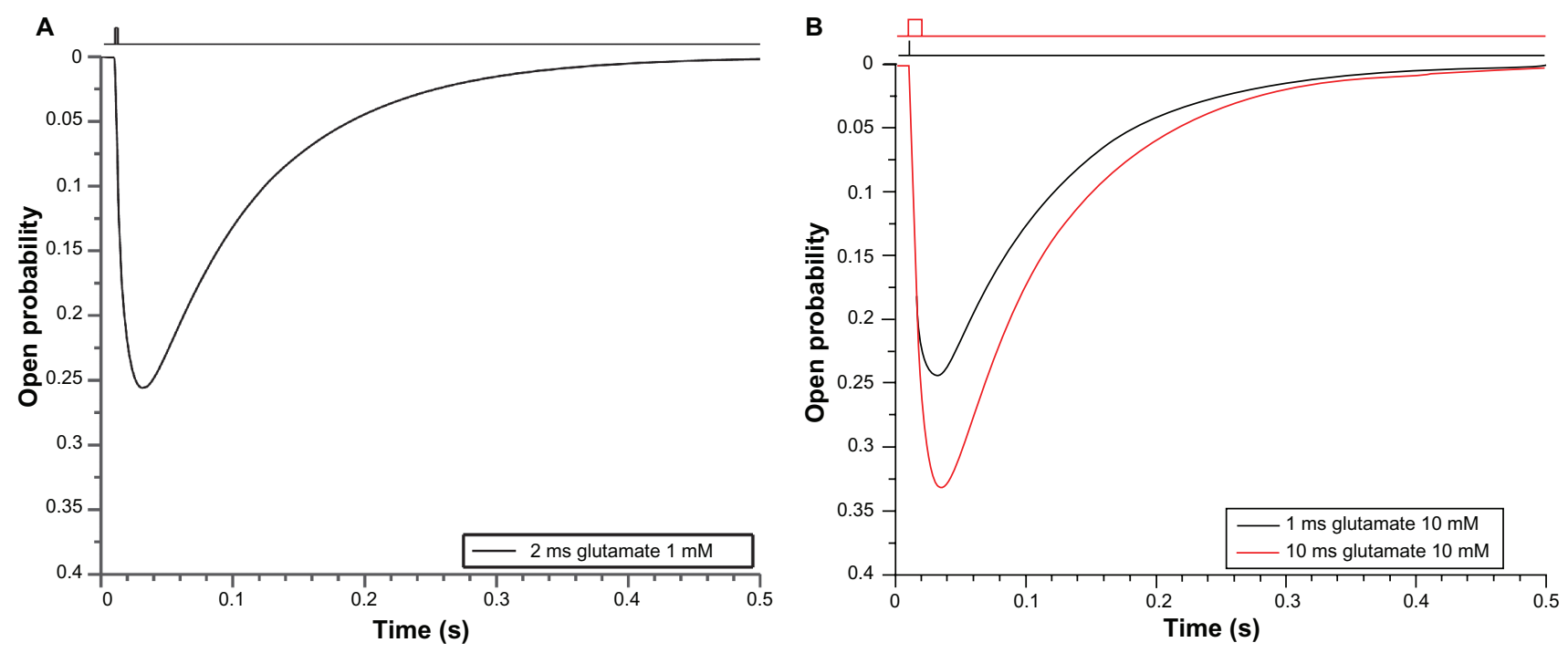

Figure 2 Time course of open probability (states Open I plus Open2) of NMDAR in response to different applications of glutamate. A) Short single pulse, 2 ms glutamate 2 mM in presence of $20 \mu \mathrm{M}$ glycine, NMDAR was set to I and Vm at $-80 \mathrm{mV}$. The predicted peak open probability was 0.256 with a decay of 92 ms. This protocol of stimulation was also used with the same kinetic scheme proposed by Schorge et al" (see Figure 9B of their paper). B) Short (I ms, black line) and long (I0 ms, red line) single pulse, glutamate $10 \mathrm{mM}$ in presence of $20 \mu \mathrm{M}$ glycine, NMDAR was set at I and Vm at $-100 \mathrm{mV}$. The predicted peaks open probabilities were 0.24 and 0.33 for short and long application, respectively. This protocol of stimulation was also used with the kinetic scheme proposed by Schorge et al " and in Wyllie et all ${ }^{16}$ (see Figure 7D and E of their paper).

course was fitted with a single exponential with a halftime decay of $92 \mathrm{~ms}$. Under these conditions (short single pulse), the simulation qualitatively and quantitatively reproduced the results reported by Schorge et $\mathrm{al}^{11}$ (figure 9B in their manuscript). The model was further tested by comparing simulated results to additional experimental data from Wyllie et $\mathrm{al}^{16}$ who also used the kinetic model of Schorge et al. ${ }^{11}$

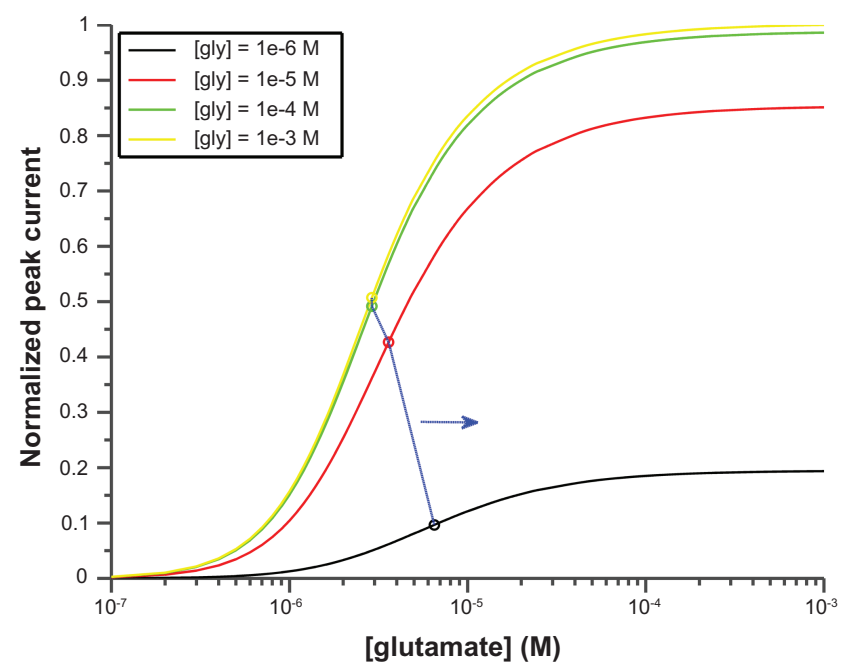

Figure 3 Effects of increasing glutamate concentrations on NMDAR responses. Peak currents were obtained from 2 second time course simulation using a single pulse stimulation (200 ms glutamate I mM, in the presence of increasing glycine concentrations (from I $\mu$ M to I mM), 25 NMDARs, $V m$ at $-75 \mathrm{mV}$, and external $\mathrm{Mg}^{2+}(\mathrm{I} \mathrm{mM})$. Results were normalized to peak current obtained with I $\mathrm{mM}$ glycine. $\mathrm{EC}_{50}$ values, indicated by color dots, were $2.9,2.9,3.6$, and $6.5 \mu \mathrm{M}$ for I mM, $0.1 \mathrm{mM}, 0.01 \mathrm{mM}$, and $0.001 \mathrm{mM}$ glycine, respectively. Blue arrow indicates the shift to the right of $\mathrm{EC}_{50}$.
In this case, simulation durations of $350 \mathrm{~ms}$ (with a delay of $50 \mathrm{~ms}$ ) were run with a short pulse of $1 \mathrm{~ms}$ (Figure 2B, black line) or a long pulse of $10 \mathrm{~ms}$ (Figure 2B, red line) of $10 \mathrm{mM}$ glutamate in the presence of $20 \mu \mathrm{M}$ of glycine. The peak open probability for a $1 \mathrm{~ms}$ glutamate stimulation was 0.24 at $18 \mathrm{~ms}$ after glutamate application with a halftime decay of $95 \mathrm{~ms}$. In contrast, a $10 \mathrm{~ms}$ long application of the same glutamate concentration produced a maximal open probability of 0.33 with a similar halftime decay of $95 \mathrm{~ms}$. These values are comparable to those of 0.29 (for maximum open probability with a short pulse) and 0.38 (for a long pulse) reported by Wyllie et al. ${ }^{16}$

We also used the model to determine the half maximal effective response $\left(\mathrm{EC}_{50}\right)$ for glutamate (Figure 3) and glycine (data not shown), by generating concentration response curves. For these 2-second-long simulations, various glutamate or glycine concentrations were applied for $200 \mathrm{~ms}$ in the presence of different concentrations of glycine or glutamate, respectively. External $\mathrm{Mg}^{2+}$ concentration was set at the physiological concentration of $1 \mathrm{mM}$ and the number of NMDARs was set at 25.5,14 For both glutamate and glycine, the $\mathrm{EC}_{50}$ was slightly dependent on the concentration of the coagonist used (from $1 \mu \mathrm{M}$ to $1 \mathrm{mM})$. In addition, the $\mathrm{EC}_{50}$ values were very close for glutamate $\left(\mathrm{EC}_{50}\right.$ values ranging from 2.9 to $\left.6.5 \mu \mathrm{M}\right)$ and glycine $\left(\mathrm{EC}_{50}\right.$ values ranging from 2.6 to $\left.6 \mu \mathrm{M}\right)$, as a result of the affinity constants used in the kinetic scheme $\left(\mathrm{K}_{\mathrm{D}}\right.$ of $3.2 \mu \mathrm{M}$ and $2.9 \mu \mathrm{M}$, respectively, for glutamate and glycine). 

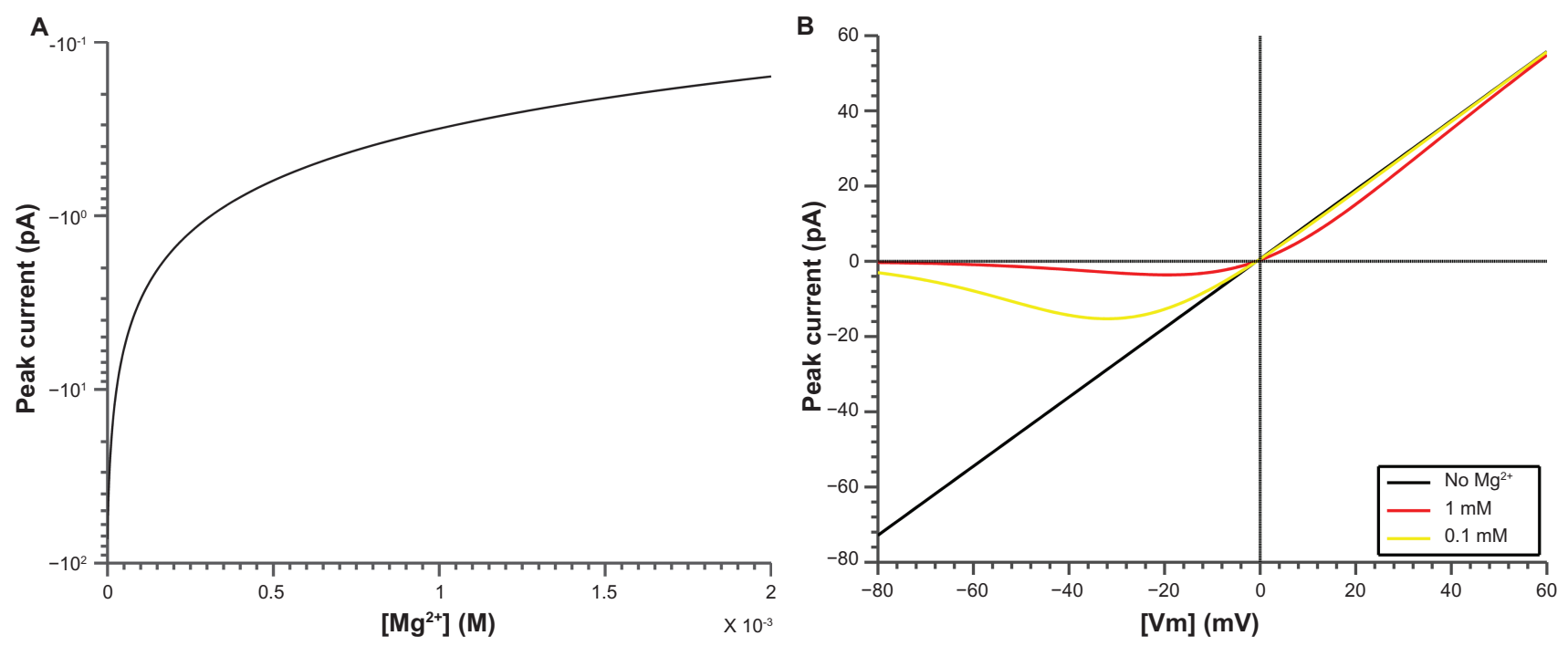

Figure 4 Effect of external $\mathrm{Mg}^{2+}$ concentration on $\mathrm{I}_{\text {NMDA }}$.A) Peak currents (pA) in response to a $2 \mathrm{~ms}$ application of $2 \mathrm{mM}$ glutamate (in the presence of $20 \mu \mathrm{M} \mathrm{glycine,} 25 \mathrm{NMDARs}$, and $\mathrm{Vm}$ at $-80 \mathrm{mV}$ ) were calculated as described under Methods on the presence of increasing external $\mathrm{Mg}^{2+}$ of up to twice the physiological concentration. B) Effect of $V \mathrm{~m}$ on peak current $(\mathrm{pA})$ in response to the same application as described in A. Black line: without external $\mathrm{Mg}^{2+}$; yellow line: $0.1 \mathrm{mM} \mathrm{Mg}^{2+}$; and red line: $1 \mathrm{mM} \mathrm{Mg}^{2+}$.

Finally, we studied the effects of external $\mathrm{Mg}^{2+}$ concentrations on $\mathrm{I}_{N M D A}$ peak currents elicited by a $2 \mathrm{~ms}$ application of $2 \mathrm{mM}$ glutamate in the presence of $20 \mu \mathrm{M}$ glycine at a $\mathrm{Vm}$ of $-80 \mathrm{mV}$ and with 25 NMDARs. As expected, NMDA peak current was strongly $\mathrm{Mg}^{2+}$-dependent, with an apparent $\mathrm{IC}_{50}$ for $\mathrm{Mg}^{2+}$ of $4.5 \mu \mathrm{M}$ (Figure 4). This value is in close agreement with the $\mathrm{K}_{\mathrm{D}}$ of $15 \mu \mathrm{M}$ at $\mathrm{Vm}$ of $-80 \mathrm{mV}$ reported by Ascher and Nowak. ${ }^{17}$

In conclusion, the kinetic model of Schorge et $\mathrm{al}^{11}$ using a single, brief application of glutamate reproduced many of the kinetic characteristics of NMDARs observed in experimental data.

\section{Optimization of NMDAR kinetic model}

By contrast, when we used long or repetitive glutamate applications, the results generated by the model were significantly different from experimental results. ${ }^{18,19}$ Simulation results shown in Figure 5A were obtained with repeated glutamate application mimicking tetanic stimulation protocols (100 hertz [Hz], 20 pulses of $1 \mathrm{~ms}$ of $1 \mathrm{mM}$ glutamate in

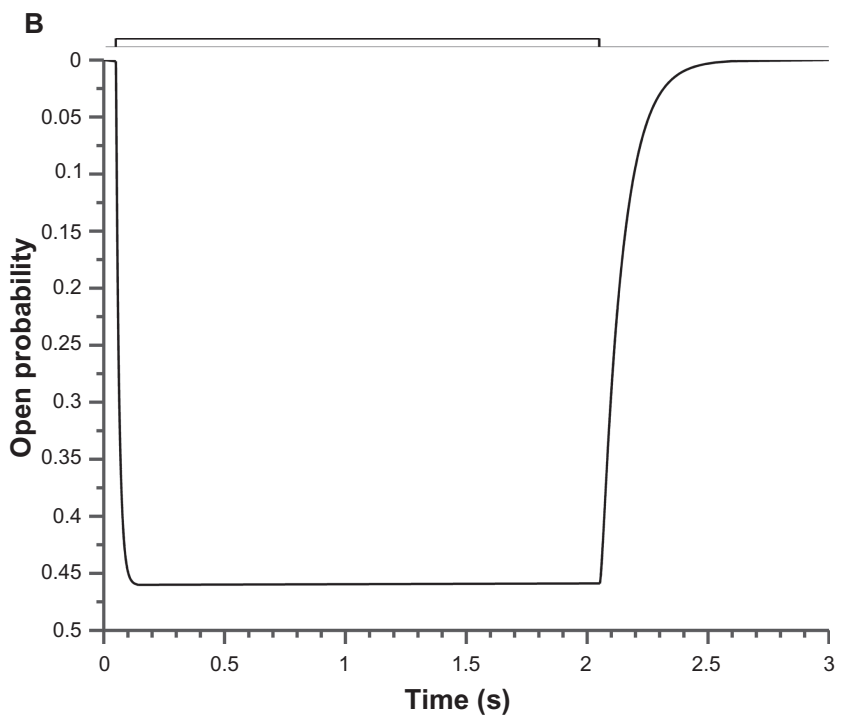

Figure 5 NMDA open probability following repetitive or long pulse glutamate applications. A) Open probability in response to a repetitive glutamate application ( $100 \mathrm{~Hz}, 20$ pulses of I ms I mM glutamate, in the presence of $20 \mu \mathrm{M}$ glycine) to a spine containing only one NMDAR. Steady maximum open probability of 0.283 was obtained after the fourth repetitive pulse and remained at this level for the remaining stimulation. B) Open probability in response to a long glutamate application ( 2 seconds, I mM glutamate, in the presence of $20 \mu \mathrm{M}$ glycine) to a spine containing only one NMDAR. Shortly after glutamate application, the open probability reaches 0.459 and remains at this level until the end of application. 
the presence of $20 \mu \mathrm{M}$ glycine) and those in Figure 5B were obtained with a long pulse stimulation (1 mM glutamate during 2 seconds in the presence of $20 \mu \mathrm{M}$ glycine). The open probability after the fourth pulse remained constant at 0.283 and did not show any desensitization of NMDARs. The same phenomenon was obtained during a long glutamate application (maximum open probability of 0.459 ). These simulated results were clearly inconsistent with experimental data where a clear desensitization of NMDARs was observed following repetitive stimulation. ${ }^{19}$

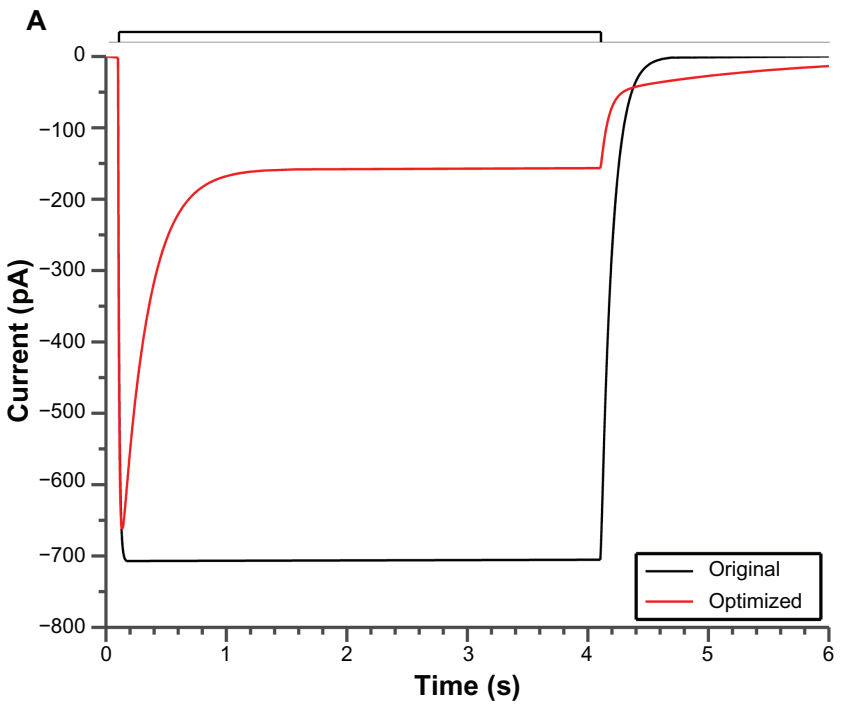

C

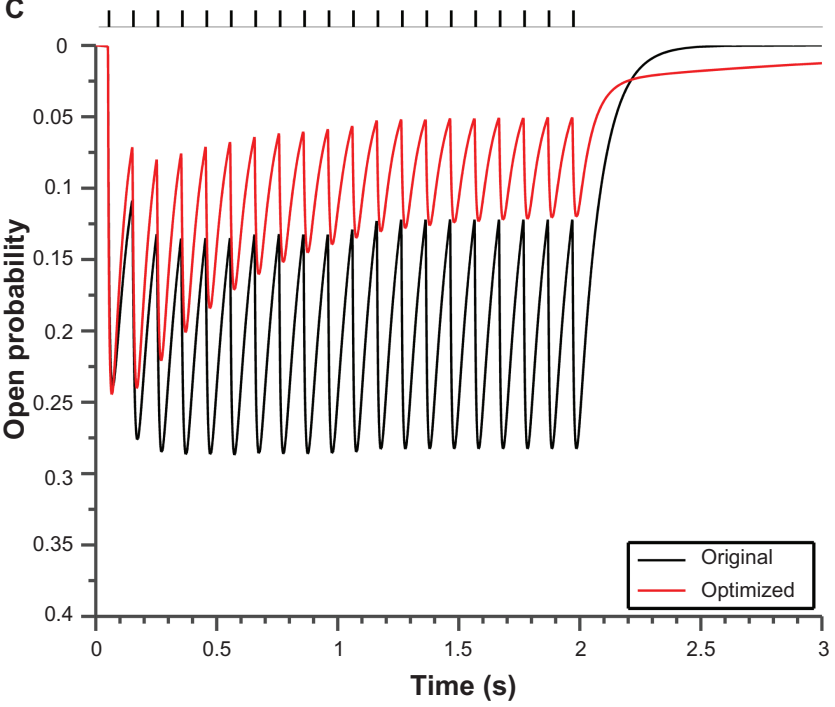

To address this issue, we modified several kinetic parameters of the model to achieve a better agreement with experimental data. In particular, we used experimental data obtained on NMDARs composed of NR1/NR2A subunits to modify the rates (for transition state J13) of desensitization and recovery from desensitization. ${ }^{18}$ Optimized values for these kinetic parameters were found to be $0.03 \mathrm{~ms}^{-1}$ and $9.5 \mathrm{e}^{-4} \mathrm{~ms}^{-1}$ for $\mathrm{d}_{\text {on }}$ and $\mathrm{d}_{\text {off }}$, respectively. With this new set of kinetic parameters, simulated results obtained with a long application of glutamate (Figure 6A) (1 mM of glutamate for
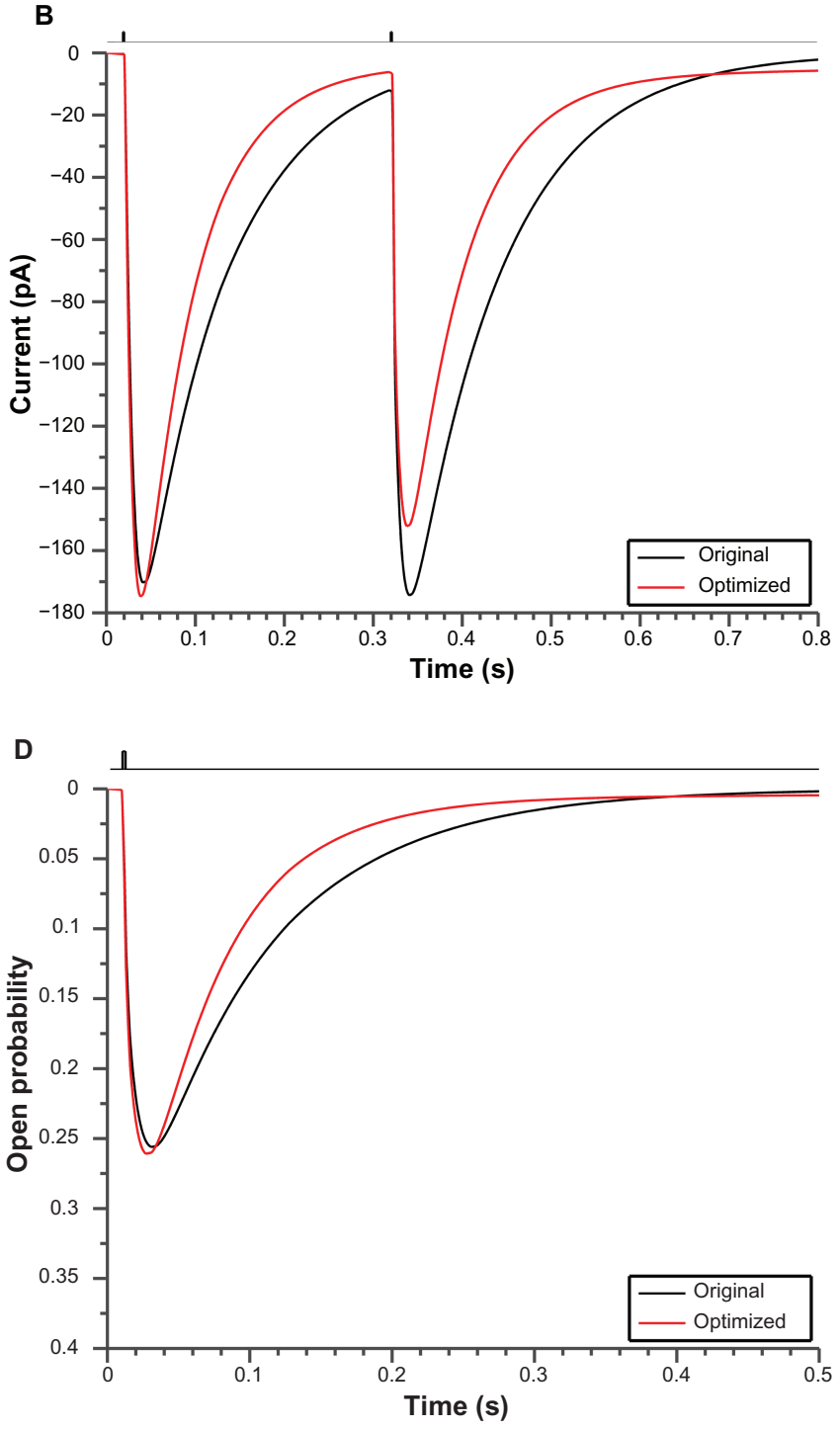

Figure 6 Optimization of model kinetic parameters. A) The effect of a long application of I mM glutamate for 4 seconds in the presence of I00 $\mu$ M glycine, I $00 \mathrm{NMDARs,Vm}$ set at $-100 \mathrm{mV}$, and external $\mathrm{Mg}^{2+}$ at $0.5 \mu \mathrm{M}$, on NMDA-mediated current was calculated as described in the Methods section and was compared between the initial (black) and optimized (red) values of the association $\left(\mathrm{d}_{\mathrm{on}}\right)$ and dissociation $\left(\mathrm{d}_{\text {off }}\right)$ constants. The pattern of the curve using optimized parameters is similar to previous results from Zhang et al ${ }^{18}$ (see Figure IB in their paper). Rapid activation is followed by biphasic decay. B) Similarly the effects of a paired pulse application of I mM glutamate for I ms with an interval of $300 \mathrm{~ms}$ between pulses in the presence of $100 \mu \mathrm{M}$ glycine, $62 \mathrm{NMDARs,Vm}$ set at $-100 \mathrm{mV}$, and $\mathrm{Mg}^{2+}$ at $0.5 \mu \mathrm{M}$, on NMDA-mediated current were calculated as described in the Methods section and were compared between the initial (black) and optimized (red) values of $d_{\text {on }}$ and $d_{\text {off }}$ parameters. The peak amplitude of the second pulse decreased by $12 \%$ as reported by Zhang et al ${ }^{18}$ (see Figure IC in their paper). C) Comparison of the effect of a repetitive glutamate application as described in Figure $5 \mathrm{~A}$ between the initial (black) and optimized (red) kinetic parameters.A clear desensitization of NMDARs was now observed. D) Comparison of the effect of a short glutamate application as described in Figure 2A between the initial (black) and optimized (red) kinetic parameters. The predicted peak open probability was $0.26 \mathrm{I}$ with a decay of 64 ms. 
4 seconds, in the presence of $10 \mu \mathrm{M}$ glycine, $\mathrm{Vm}$ of $-100 \mathrm{mV}$, external $\mathrm{Mg}^{2+}$ concentration of $0.5 \mu \mathrm{M}$, and 100 NMDARs) or a paired pulse application of glutamate $(1 \mathrm{mM}$ during 1 $\mathrm{ms}$ with an interval between pulse of $300 \mathrm{~ms}$, in the presence of $10 \mu \mathrm{M}$ glycine, $\mathrm{Vm}$ of $-100 \mathrm{mV}$, external $\mathrm{Mg}^{2+}$ of $0.5 \mu \mathrm{M}$, and 62 NMDARs) (Figure 6B) were in good agreement with experimental data from Zhang et al. ${ }^{18} \mathrm{~A}$ clear desensitization of NMDARs was now observed using a long application of glutamate (peak current of $-662 \mathrm{pA}$, followed by a plateau at $-159 \mathrm{pA}$ for the duration of glutamate application). In the paired pulse paradigm, a $12 \%$ decrease in peak amplitude in response to the second glutamate application was observed as compared to the response to the first pulse. ${ }^{20,18}$ Interestingly, simulated results obtained with repeated glutamate application (as reported in Figure 5A) using these new sets of parameter values showed a clear desensitization (Figure 6C), while results obtained with a single pulse (as reported in Figure 2A) were very similar to those obtained with the initial set of parameters, with a maximum open probability of 0.261 and a halftime decay of $64 \mathrm{~ms}$ (fitted with a single exponential) (Figure 6D).

\section{Effect of a competitive antagonist (AP5)}

We then used the model to analyze several features of AP5, a competitive antagonist, on NMDARs properties. Association and dissociation rate constants $\left(\mathrm{k}_{\text {on }}\right.$ and $\mathrm{k}_{\text {off }}$ ) for AP5, were set at $0.38 \mathrm{mM}^{-1} \cdot \mathrm{ms}^{-1}$ and $0.02 \mathrm{~ms}^{-1}$, respectively based on published experimental results. ${ }^{21}$ Open probabilities (Figure 7A) obtained from the time course of simulations in response to a $4 \mathrm{~ms}$ application of $1 \mathrm{mM}$ glutamate in the presence of $13 \mu \mathrm{M}$ glycine and no APV, $20 \mu \mathrm{M}$ APV, or $30 \mu \mathrm{M}$ APV provided a clear dosedependent reduction in NMDAR-mediated responses. Peak open probabilities decreased by $32 \%$ (at $20 \mu \mathrm{M}$ AP5) and $45 \%$ (at $30 \mu \mathrm{M}$ AP5). To quantify AP5-mediated inhibition of NMDARs, we calculated the cumulative inhibition of glutamate-elicited currents over time, under the same conditions. These data were used to generate dose-response curves (Figure 7B). The estimated $\mathrm{IC}_{50}$ value for AP5 was $35 \mu \mathrm{M}$, in good agreement with the value of $30 \mu \mathrm{M}$ found in the literature. ${ }^{7}$

To analyze the effect of stimulation frequency (repetitive application of glutamate) on the inhibitory effect of AP5, we applied 25 pulses (1 $\mathrm{ms}$ of $1 \mathrm{mM}$ glutamate) at frequencies ranging from 10 to $100 \mathrm{~Hz}$. The number of NMDARs was set at 25, external $\mathrm{Mg}^{2+}$ concentration at $1 \mathrm{mM}$, and $\mathrm{Vm}$ at $-60 \mathrm{mV}$. Simulations were run in the presence of $13 \mu \mathrm{M}$ glycine for 5 seconds. To quantify the effect of AP5, we calculated the cumulative percentage of inhibition of NMDAR-mediated current. Dose-response curves for AP5 (Figure 8A) were markedly shifted to the right with increasing frequency of stimulation up to 100 $\mathrm{Hz}$. The $\mathrm{IC}_{50}$ values for AP5 correspondingly increased from $0.12 \mathrm{mM}$ to $0.45 \mathrm{mM}$ at $10 \mathrm{~Hz}$ and $100 \mathrm{~Hz}$, respectively. At very high frequencies $(>100 \mathrm{~Hz})$, we observed an inversion of this phenomenon (data not shown). On the other hand, our simulations showed that the inhibitory effects of AP5 $(0.1 \mathrm{mM})$ were independent of $\mathrm{Vm}$ in the absence of $\mathrm{Mg}^{2+}$

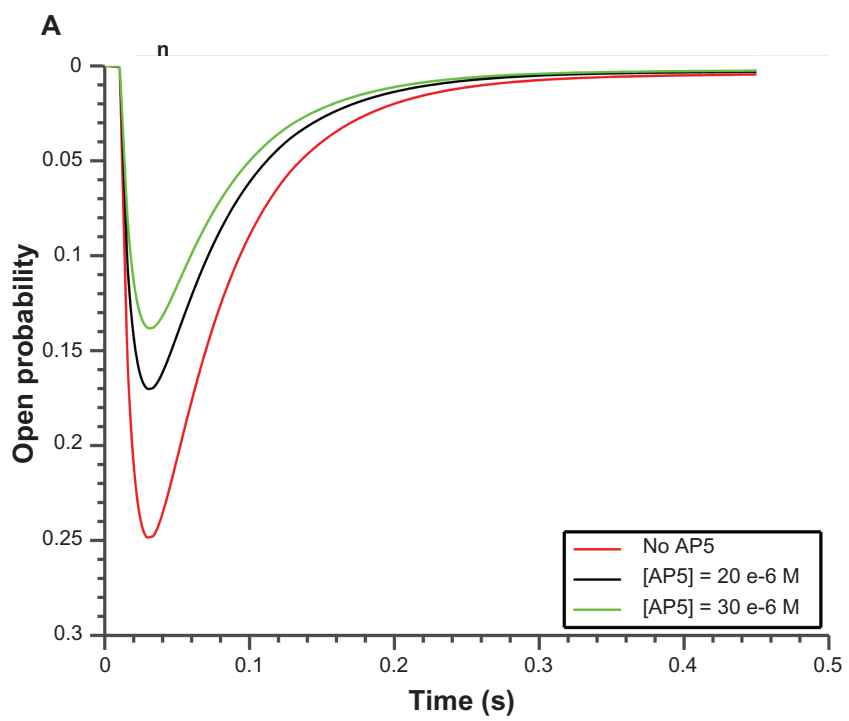

B

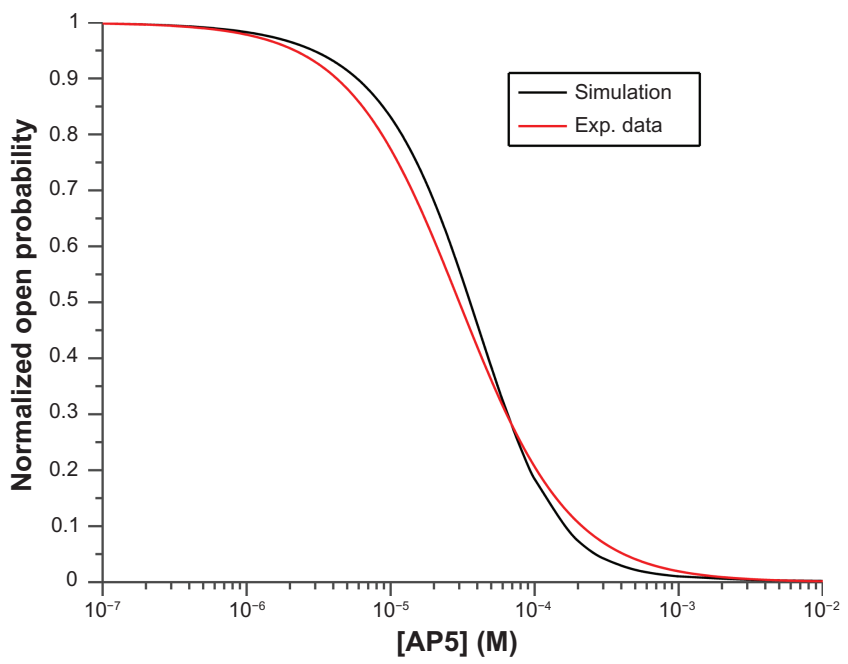

Figure 7 Effects of AP5 on NMDAR-mediated responses. A) Time course of open probability in response to a brief application of I mM glutamate for 4 ms, in the presence of I $3 \mu \mathrm{M}$ glycine of one NMDAR channel and two concentrations of AP5: $20 \mu \mathrm{M}$ (black line) and $30 \mu \mathrm{M}$ (green line). With the highest AP5 concentration, open probability decreased by $\sim 50 \%$. B) Dose-response curves for peak open probability (normalized) under the same conditions. Red line: experimental data from Harrison and Simmonds ${ }^{37}$ with an $I C_{50}$ value of $30 \mu \mathrm{M}$; black line: simulated results $\left(\mathrm{IC}_{50}\right.$ value of $\left.35 \mu \mathrm{M}\right)$. 
A

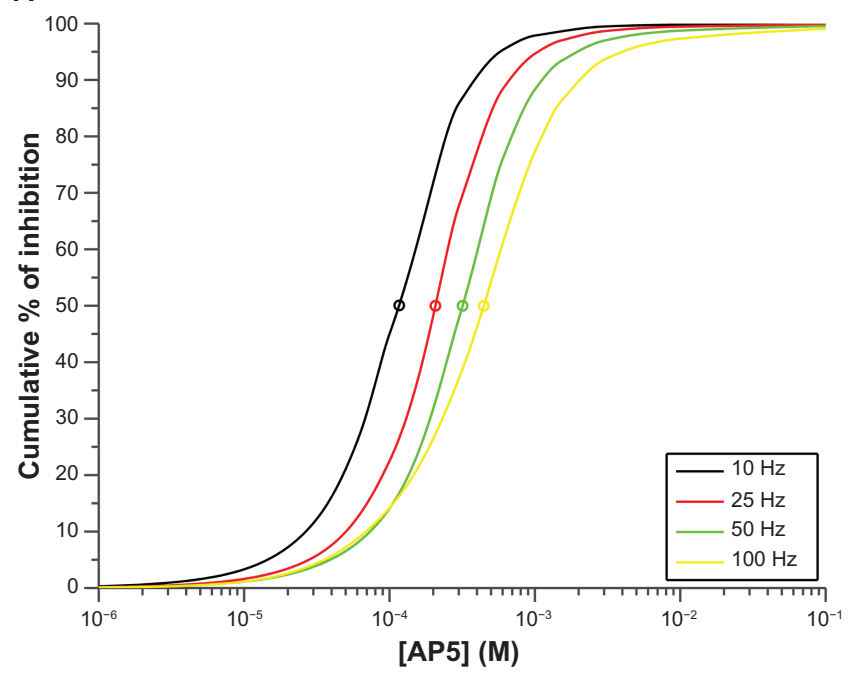

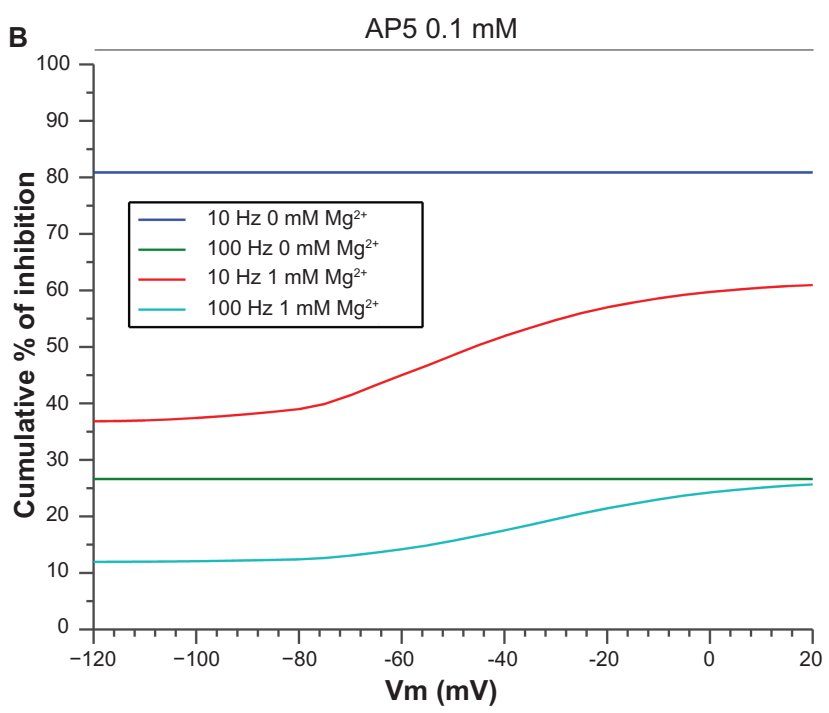

Figure 8 Effect of stimulation frequency and membrane potential on AP5-mediated inhibition of NMDAR currents. A) The effects of increasing AP5 concentrations at different stimulation frequencies on NMDAR-mediated responses were calculated as described under Methods. Repetitive application of glutamate (25 pulses, I ms I mM glutamate, in the presence of $13 \mu \mathrm{M}$ glycine, $25 \mathrm{NMDARs}, \mathrm{Mg}^{2+}$ set at I mM, Vm set at $-60 \mathrm{mV}$ ) induced a right shift of the concentration-response curves (with increased IC ${ }_{50}$ labeled by dots) with increasing frequency (stimulation duration 5 seconds). The calculated $\mathrm{IC}_{50}$ values were $0.12,0.2 \mathrm{I}, 0.3 \mathrm{I}$, and $0.45 \mathrm{mM}$ for $10,25,50$, and I00 $\mathrm{Hz}$, respectively. B) The effects of $\mathrm{Vm}$ on AP5-mediated inhibition of NMDAR-mediated responses in the absence or presence of I mM Mg ${ }^{2+}$ were calculated as described under Methods. AP5 concentration was set at $100 \mu \mathrm{M}$ and frequency of stimulation was set at $10 \mathrm{~Hz}$ and $100 \mathrm{~Hz}$. The same application was used as described previously. In the absence of external $\mathrm{Mg}^{2+}$, the effects of AP5 were not voltage-dependent.

and were only slightly dependent on $\mathrm{Vm}$ in the presence of $1 \mathrm{mM} \mathrm{Mg}^{2+}$ (Figure 8B).

\section{Effect of a noncompetitive antagonist (memantine)}

To contrast the effects of competitive antagonists, we then tested the effect of a noncompetitive antagonist,

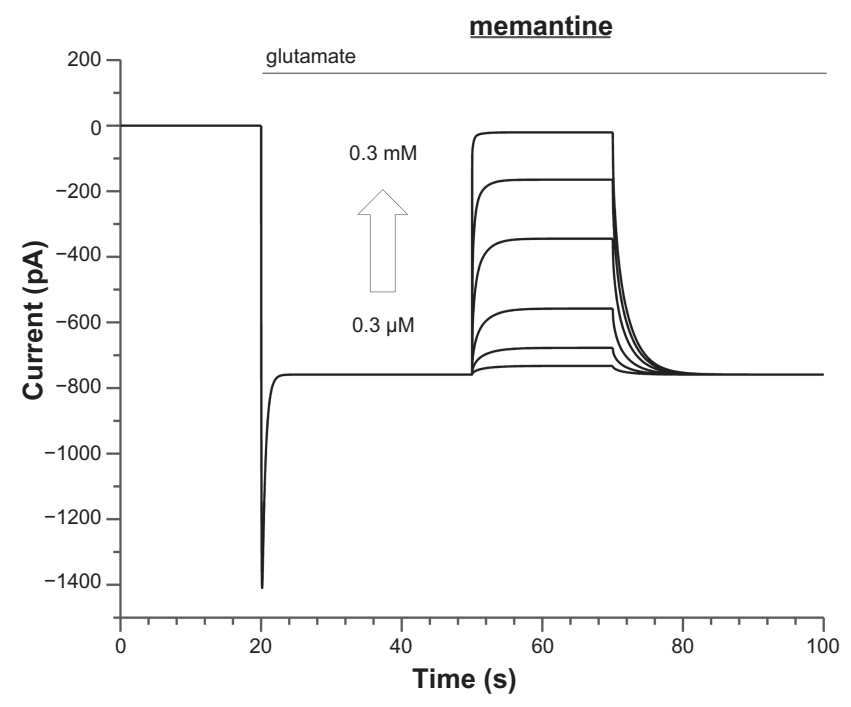

Figure 9 Effect of memantine on time course and amplitude of $\mathrm{I}_{\mathrm{NMDA}} \cdot$ Various concentrations of memantine (ranging from $0.3 \mu \mathrm{M}$ to $0.3 \mathrm{mM}$ ) were applied after a delay of 30 seconds following the application of glutamate $(0.3 \mathrm{mM})$ in the presence of $2 \mu \mathrm{M}$ glycine, with a number of NMDARs set at $900, \mathrm{Vm}$ at $-70 \mathrm{mV}$, and in the absence of $\mathrm{Mg}^{2+}$. The maximum memantine concentration used $(0.3 \mathrm{mM})$ totally blocked the opening of the NMDAR channel. namely memantine, on glutamate-mediated NMDAR responses. We considered that memantine bind to the NMDAR channel in a voltage-dependent manner as previously shown. ${ }^{6}$ The kinetic scheme from Figure 1 was modified to incorporate a number of transition states due to the presence of memantine (Supplemental data 1). With this modification, we verified that an application of increasing concentrations of memantine reversed the activation of the NMDAR channel produced by a constant application of glutamate. Time course simulations in Figure 9 were run with a long application ( 80 seconds of $0.3 \mathrm{mM}$ glutamate in the presence of $2 \mu \mathrm{M}$ glycine). The number of NMDARs was set at 900 and $\mathrm{Vm}$ at $-70 \mathrm{mV}$ in the absence of $\mathrm{Mg}^{2+}$. Memantine (0.3 to $\left.300 \mu \mathrm{M}\right)$ was applied for 20 seconds. Memantine dose-dependently blocked NMDAR and at $300 \mu \mathrm{M}$ memantine completely blocked NMDAR-mediated current.

The influence of both frequencies of stimulation and Vm on the potency of memantine to inhibit NMDAR channel opening was analyzed (Figures 10A and B). First, the inhibitory effects of memantine were again quantified by calculating the cumulative inhibition of NMDAR-mediated current during a 5 second duration of stimulation. The parameters of stimulation consisted of the repetitive application of glutamate concentration at 10 to $200 \mathrm{~Hz}$, as previously used for AP5. As with AP5, dose-response curves for memantine (Figure 10A) were also shifted to the 

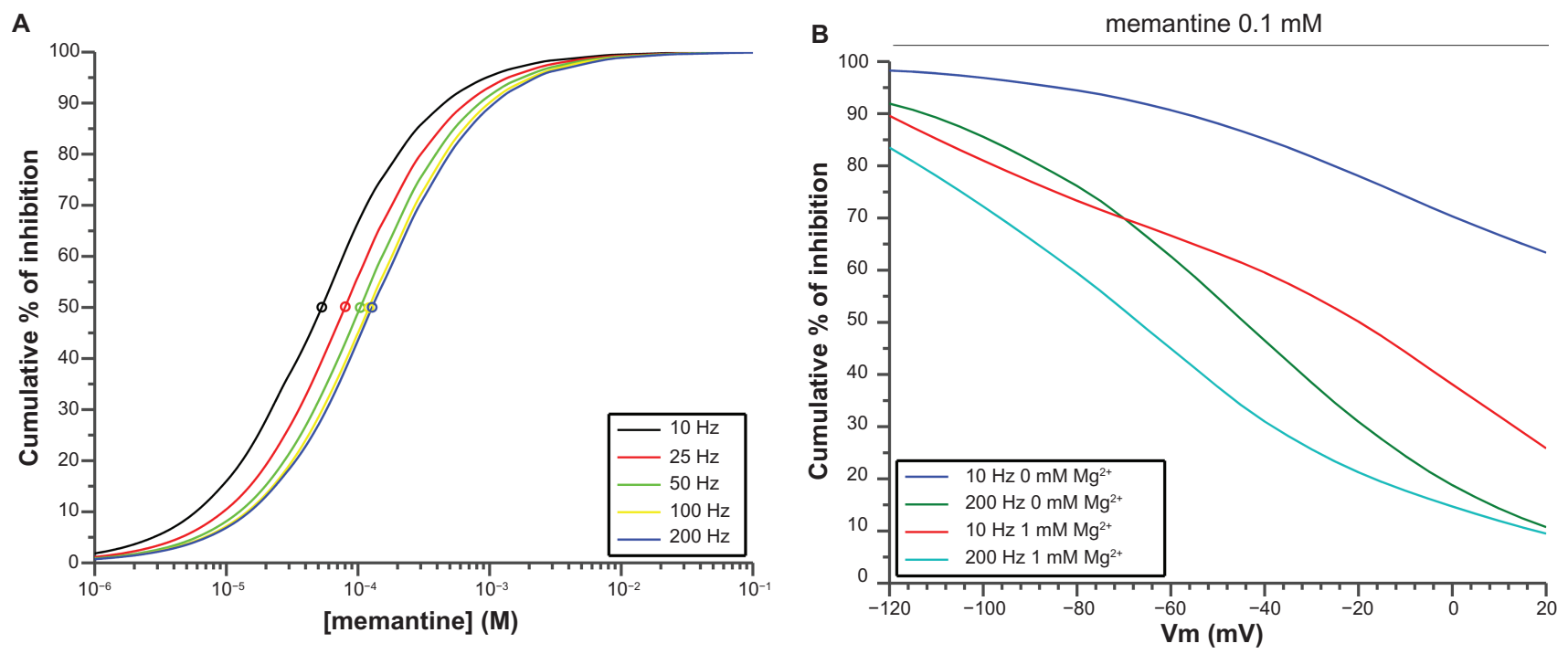

Figure 10 Effect of stimulation frequency and membrane potential on memantine-mediated inhibition of NMDAR currents. A) The effects of increasing memantine concentrations at different stimulation frequencies on NMDAR-mediated responses were calculated as described under Methods. NMDAR-mediated responses were obtained with repetitive applications of glutamate under the same conditions as those used for AP5 in Figure 8. Increasing application frequency induced a right shift of the concentration-response curves (with increased IC $\mathrm{IC}_{50}$, labeled with dots). The calculated IC $\mathrm{I}_{50}$ values were 52.5, 79, I05, I25, and I32 $\mu \mathrm{M}$ for I0, 25, 50, I00, and 200 Hz, respectively. B) The effects of $\mathrm{Vm}$ on memantine-mediated inhibition of NMDAR-mediated responses in the absence or presence of I mM Mg $\mathrm{g}^{2+}$ were calculated as described under Methods. Memantine concentration was set at $100 \mu \mathrm{M}$ and frequency of stimulation was set at $10 \mathrm{~Hz}$ and $200 \mathrm{~Hz}$. The same conditions of glutamate applications were used as above. In the presence or absence of external $\mathrm{Mg}^{2+}$, the effects of memantine remained voltage-dependent.

right with increasing frequencies and the $\mathrm{IC}_{50}$ for memantine increased from $0.052 \mathrm{mM}(10 \mathrm{~Hz})$ to $0.132 \mathrm{mM}(200$ $\mathrm{Hz})$. In contrast to AP5, the inhibitory effect of $0.1 \mathrm{mM}$ memantine was clearly dependent on Vm (Figure 10B, red and cyan lines) and was markedly modified in the presence of $\mathrm{Mg}^{2+}$ (Figure 10B, blue and green lines). Thus, more detailed investigations of $\mathrm{Vm}$ dependency showed that the dose-response curves for memantine were also shifted to the right and the $\mathrm{IC}_{50}$ escalated with increasing $\mathrm{Vm}$ at both 10 (Figure 11A) and $200 \mathrm{~Hz}$ (Figure 11B). The effect of $\mathrm{Vm}$ was larger at $200 \mathrm{~Hz}$ than at $10 \mathrm{~Hz}$. Thus, the $\mathrm{IC}_{50}$ values for memantine increased from $12.5 \mu \mathrm{M}$ at $-120 \mathrm{mV}$ to $285.5 \mu \mathrm{M}$ at $+20 \mathrm{mV}$ using $10 \mathrm{~Hz}$ stimulation. When the stimulation frequency was $200 \mathrm{~Hz}$ (Table 2), the $\mathrm{IC}_{50}$ for memantine increased from $20.5 \mu \mathrm{M}$ to $1.294 \mu \mathrm{M}$ at $+20 \mathrm{mV}$.
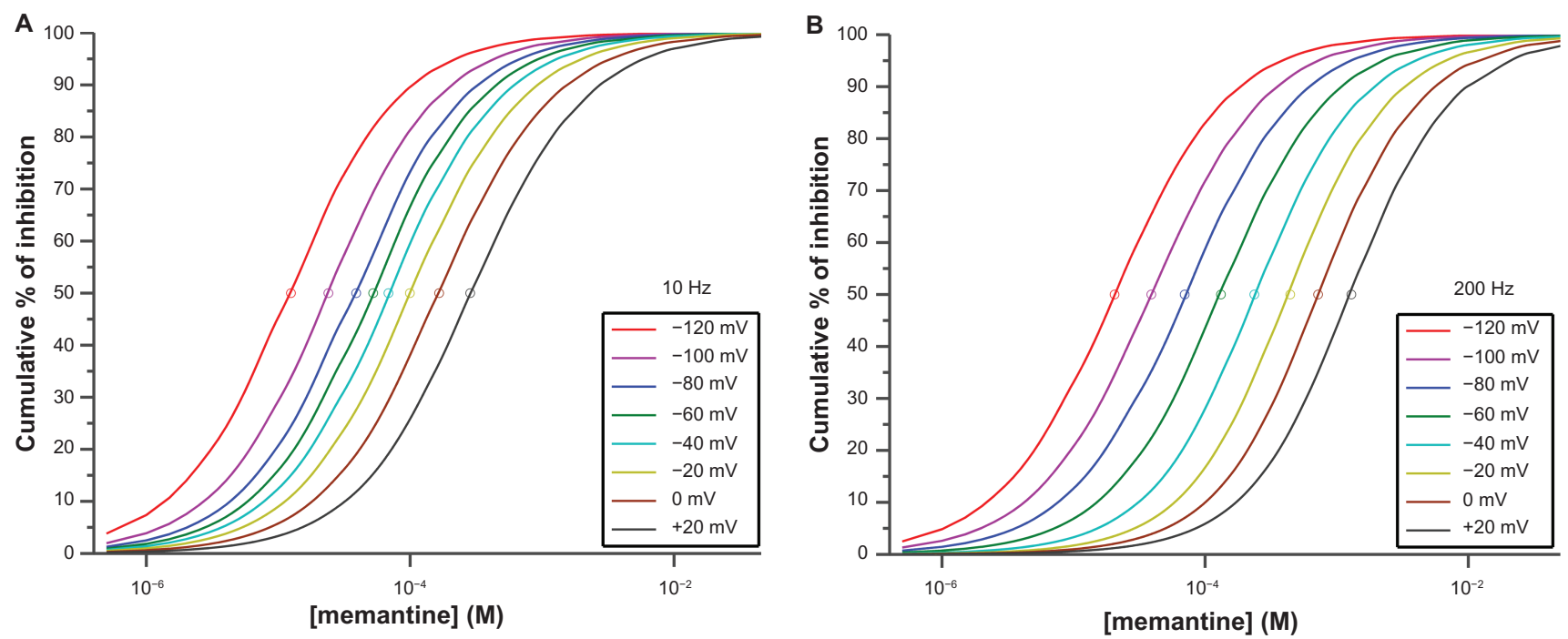

Figure I I Effects of membrane potential on memantine-mediated inhibition of NMDAR function.

The cumulative inhibition of various concentrations of memantine at different membrane potentials (ranging from $-120 \mathrm{mV}$ to $+20 \mathrm{mV}$ ) on NMDAR currents produced by a repetitive application of glutamate was calculated as described under Methods (same conditions as previously used). A) $10 \mathrm{~Hz}$. B) $200 \mathrm{~Hz}$. The calculated IC ${ }_{50}$ increased with

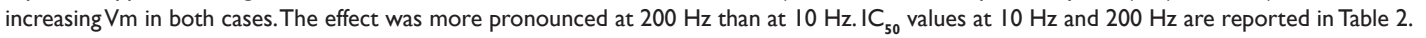


Table $2 \mathrm{IC}_{50}$ values for memantine as a function of membrane potential and frequency of stimulation (extracted from Figure II)

\begin{tabular}{|c|c|c|c|c|c|c|c|c|}
\hline & $-120 \mathrm{mV}$ & $-100 \mathrm{mV}$ & $-80 \mathrm{mV}$ & $-60 \mathrm{mV}$ & $-40 \mathrm{mV}$ & $-20 \mathrm{mV}$ & $0 \mathrm{mV}$ & $+20 \mathrm{mV}$ \\
\hline $\mathrm{IC}_{50}(\mu \mathrm{M})$ at $10 \mathrm{~Hz}$ & 12.5 & 24 & 39 & 52.5 & 68.5 & 99.5 & 166 & 285.5 \\
\hline $\mathrm{IC}_{50}(\mu \mathrm{M})$ at $200 \mathrm{~Hz}$ & 20.5 & 39 & 70 & 132 & 236.5 & 443.5 & 722.5 & 1294 \\
\hline
\end{tabular}

\section{Discussion}

In the present study, we developed a complete kinetic model of NMDARs that we used to analyze a number of features reported in the literature, especially the differential effects of a competitive (AP5) and a noncompetitive inhibitor (memantine) of the receptor. Our model was based on several previous studies (simulations and experimental data) that analyzed the characteristics of NMDARs (NR1/NR2A subtype) under a number of conditions (stimulation protocol, $\left[\mathrm{Mg}^{2+}\right]$, glutamate and glycine concentration, etc). We were particularly interested in studying the effects of stimulation frequency on the inhibitory potency of both types of antagonists. Experimental results indicated that this parameter is critical to account for the beneficial effects of memantine against $\mathrm{AD}$, while it could also account for the failure of non subunit-selective competitive antagonists to provide neuroprotection against excitotoxicity.

\section{Model validation}

The complete model resulted in a set of differential equations with a relatively large number of parameters. While most parameters were already reported in the literature, we needed to optimize some of the parameters in order to reproduce some experimental results. It is important to stress that the relatively low cost and speed (few minutes) of biosimulation compared to those of actual experiments (days) allowed us to rapidly test a large range of parameter values and experimental conditions, facilitating validation and optimization.

We first validated our model by examining its ability to reproduce a large variety of experimental data. For example, we verified that, when using a paired pulse stimulation protocol ( $1 \mathrm{~ms}$ glutamate $1 \mathrm{mM}$ with an interval between pulses of $10 \mathrm{~ms}$ in the presence of $100 \mu \mathrm{M}$ glycine) the ratio of open probability between the second and the first pulse was similar to previously published experimental data (Supplemental data 2). ${ }^{22}$ Simulated results obtained with our model were also compared with results obtained after short ( $1 \mathrm{~ms}$ glutamate $1 \mathrm{mM}$ or $10 \mathrm{mM}$ ) and long (4 second glutamate $1 \mathrm{mM})$ pulses of glutamate application, ${ }^{20}$ longer pulse (40 second glutamate $3 \mu \mathrm{M})$ and repetitive $(100 \mathrm{~Hz}$ for 0.5 second, $1 \mathrm{~ms}$ glutamate $10 \mathrm{mM}$ ) applications of glutamate, ${ }^{19}$ longer (10 second glutamate $0.1 \mathrm{mM}$ ) pulse applications of glutamate, ${ }^{23}$ and applications of increased concentrations of glutamate and glycine. ${ }^{24,25}$ Due to space limitations, not all simulated results were reported in the present study. However, it is very important to note that the pattern of results generated by our model can handle most protocols of NMDAR stimulation routinely used to assess their function. Even when experimental conditions had to be modified/optimized in order to match those used in various publications (ie, concentration of $\mathrm{Mg}^{2+}$ or concentration of glycine or number of NMDARs) all simulated results were in good agreement with experimental data. In future experiments, it would be of interest to enhance the complexity of the model by exploring the regulation of the NMDAR current by zinc $\left(\mathrm{Zn}^{2+}\right)$, spermine, or ATP. ${ }^{26,27}$

\section{Influence of stimulation frequency and membrane potential on the effects of competitive antagonists}

Many publications have reported the effects of competitive antagonists such as AP5 on NMDAR function under a wide range of experimental conditions. ${ }^{28,29}$ Our simulated results were generally in good agreement with these previous findings. As expected, AP5 inhibitory potency was independent of membrane potential. However, inhibitory potency was strongly dependent on stimulation frequency. The predicted $\mathrm{IC}_{50}$ values for AP5 increased with heightened stimulation frequency. Surprisingly, at very high stimulation frequencies $(200-400 \mathrm{~Hz})$, this effect was reversed and the $\mathrm{IC}_{50}$ for AP5 decreased. The reason for this effect is not totally clear, but could be due to an interaction between receptor desensitization and increased glutamate concentrations at increased stimulation frequencies. In any event, these results suggest that during periods of overstimulation of NMDARs, as could occur during epileptic seizures, stroke, or excitotoxicity, the inhibitory potency of competitive antagonists would significantly decrease..$^{30,31}$ This could account for the failure of these antagonists in clinical trials, especially with respect to stroke. Assuming that under stroke conditions the firing frequency of neurons in the damaged brain area significantly increases, the clinical dose of NMDAR antagonists, such as selfotel, should be several fold higher than that determined under normal conditions, 
therefore increasing the occurrence of potentially toxic side effects. ${ }^{32,33}$

\section{Influence of stimulation frequency and membrane potential on the effects of noncompetitive antagonists}

Today, the noncompetitive antagonist, memantine, is one of the most commonly prescribed drugs to treat mild to moderate $\mathrm{AD}$ patients. Regarding the critical role of NMDARs in learning and memory, the use of an antagonist of NMDARs to treat this disease characterized by major impairment of cognitive functions has been the subject of many debates. In particular, the differences between a rapid off-rate antagonist, such as memantine, and a slow off-rate one, such as MK-801, have been discussed to account for the different patterns of inhibition produced by these two types of antagonists. ${ }^{34}$ Our results showed that the inhibitory potency of memantine is markedly dependent on both membrane potential and stimulation frequency. This supports the notion that memantine provides a tonic blockade of NMDARs under basal conditions, which could account for its neuroprotective properties. In contrast, the inhibitory potency is decreased by more than 100 fold under conditions of membrane depolarization and high frequency stimulation of NMDARs, conditions that are presumably associated with learning new information. ${ }^{34}$ This mechanism would therefore explain why memantine does not impair learning and memory. This hypothesis was previously advanced by several laboratories and our results certainly provide quantitative evidence for its validity. ${ }^{34,35}$

\section{Usefulness of a detailed model of NMDARs}

More generally, the detailed kinetic model of NMDARs we have developed could provide a very useful tool to determine the influence of a variety of compounds acting on various elements of the model on NMDAR function and under a variety of experimental conditions. While the choice of some of the parameters was guided by the ability to reproduce a large set of experimental data, we did not necessarily evaluate the whole space of parameter values. A relatively similar model of NMDARs has been used to address the question of the potential differential roles of NR2- and NR2B-containing receptors in LTP induction, ${ }^{8}$ while a different kinetic model was used to explore the role of NMDARs in spike timing-dependent plasticity. ${ }^{36}$ Furthermore, additional binding sites could be easily implemented in order to study the effects of other regulators of the receptors, such as spermine, $\mathrm{Zn}^{2+}$, or other allosteric modulators. In addition, the model we developed could be used to determine the influence of various kinetic parameters (rates of activation, deactivation, or desensitization) on NMDAR function using a wide range of stimulation. In particular, it is clear that the rate of deactivation $\left(\mathrm{J} 18, \mathrm{k}_{\text {off }}\right)$ appears to have a significant effect on NMDAR function. Another important conclusion of our simulation is the need to take into account the dynamic aspects of receptor properties and of neuronal activity to understand the mode of action of compounds acting at different sites of the receptors. Specifically, while it is clear that a competitive antagonist might provide a powerful blockade of receptor under equilibrium conditions, it might lose its potency under conditions of high frequency stimulation, which might be present under pathological conditions. Ultimately, the model we have developed could be used to identify new targets to increase or decrease NMDAR function.

\section{Acknowledgments}

Supported by grants R01NS057128-01A2 from NINDS to MB, and P41 EB001978-24 from NIBIB to TWB; Rhenovia obtained financing by the French Ministry of Research, OSEO, the Region Alsace, the European Community, Altran-Est, the French National Agency of Research and Technology (ANRT) with a Cifre grant (RG), Alsace Business Angels, and SODIV. The authors wish to thanks Dr AF Keller for helpful discussions.

\section{Disclosure}

$\mathrm{MB}, \mathrm{TB}$, and JMB have a conflict of interest.

The University of Southern California holds an equity interest in Rhenovia Pharma and has also received licensing income from Rhenovia Pharma. For more information, visit www.rhenovia.com.

\section{References}

1. Berger TW. Long-term potentiation of hippocampal synaptic transmission affects rate of behavioral learning. Science. 1984;224:627-630.

2. Lynch G, Baudry M. The biochemistry of memory: a new and specific hypothesis. Science. 1984;224:1057-1063.

3. Dingledine R, Borges K, Bowie D, Traynelis SF. The glutamate receptor ion channels. Pharmacol Rev. 1999;51:7-61.

4. Ciabarra AM, et al. Cloning and characterization of chi-1: a developmentally regulated member of a novel class of the ionotropic glutamate receptor family. J Neurosci. 1995;15:6498-6508.

5. Cull-Candy SG, Leszkiewicz DN. Role of distinct NMDA receptor subtypes at central synapses. Sci STKE. 2004;255:re16.

6. Kotermanski SE, Johnson JW. $\mathrm{Mg}^{2+}$ imparts NMDA receptor subtype selectivity to the Alzheimer's drug memantine. J Neurosci. 2009; 29:2774-2779. 
7. Morris RG. Synaptic plasticity and learning: selective impairment of learning rats and blockade of long-term potentiation in vivo by the N-methyl-D-aspartate receptor antagonist AP5. J Neurosci. 1989;9: 3040-3057.

8. Santucci DM, Raghavachari S. The effects of NR2 subunit-dependent NMDA receptor kinetics on synaptic transmission and CaMKII activation. PLoS Comput Biol. 2008;4:e1000208.

9. Danysz W, Parsons CG. The NMDA receptor antagonist memantine as a symptomatological and neuroprotective treatment for Alzheimer's disease: preclinical evidence. Int J Geriatr Psychiatry. 2003;18:S23-S32.

10. Rammes G, Danysz W, Parsons CG. Pharmacodynamics of memantine: an update. Curr Neuropharmacol. 2008;6:55-78.

11. Schorge S, Elenes S, Colquhoun D. Maximum likelihood fitting of single channel NMDA activity with a mechanism composed of independent dimers of subunits. J Physiol. 2005;569:395-418.

12. Liu L, et al. Role of NMDA receptor subtypes in governing the direction of hippocampal synaptic plasticity. Science. 2004;304:1021-1024.

13. Bouteiller JM, et al. Modeling glutamatergic synapses: insights into mechanisms regulating synaptic efficacy. $J$ Integr Neurosci. 2008;7:185-197.

14. Hucka M, et al. The systems biology markup language (SBML): a medium for representation and exchange of biochemical network models. Bioinformatics. 2003;19:524-531.

15. Jahr CE, Stevens CF. Voltage dependence of NMDA-activated macroscopic conductances predicted by single-channel kinetics. J Neurosci. 1990;10:3178-3182.

16. Wyllie DJ, Johnston AR, Lipscombe D, Chen PE. Single-channel analysis of a point mutation of a conserved serine residue in the S2 ligand-binding domain of the NR2A NMDA receptor subunit. JPhysiol. 2006;574:477-489.

17. Ascher P, Nowak L. The role of divalent cations in the N-methylD-aspartate responses of mouse central neurones in culture. J Physiol. 1988;399:247-266.

18. Zhang W, Howe JR, Popescu GK. Distinct gating modes determine the biphasic relaxation of NMDA receptor currents. Nat Neurosci. 2008;11:1373-1375.

19. Frizelle PA, Chen PE, Wyllie DJ. Equilibrium constants for (R)-[(S)1-(4-bromo-phenyl)-ethylamino]-(2,3-dioxo-1,2,3,4-tetrahydroquino xalin-5-yl)-methyl]-phosphonic acid (NVP-AAM077) acting at recombinant NR1/NR2A and NR1/NR2B N-methyl-D-aspartate receptors: Implications for studies of synaptic transmission. Mol Pharmacol. 2006;70:1022-1032.

20. Anson LC, Schoepfer R, Colquhoun D, Wyllie DJ. Single-channel analysis of an NMDA receptor possessing a mutation in the region of the glutamate binding site. J Physiol. 2000;527 Pt 2:225-237.

21. Benveniste M, Mienville JM, Sernagor E, Mayer ML. Concentration-jump experiments with NMDA antagonists in mouse cultured hippocampal neurons. J Neurophysiol. 1990;63:1373-1384.
22. Popescu G, Robert A, Howe JR, Auerbach A. Reaction mechanism determines NMDA receptor response to repetitive stimulation. Nature. 2004;430:790-793.

23. Fayyazuddin A, Villarroel A, Le Goff A, Lerma J, Neyton J. Four residues of the extracellular N-terminal domain of the NR2A subunit control high-affinity $\mathrm{Zn}^{2+}$ binding to NMDA receptors. Neuron. 2000;25:683-694

24. Gielen M, et al. Structural rearrangements of NR1/NR2A NMDA receptors during allosteric inhibition. Neuron. 2008;57:80-93.

25. Madry C, Mesic I, Betz H, Laube B. The N-terminal domains of both NR1 and NR2 subunits determine allosteric $\mathrm{Zn}^{2+}$ inhibition and glycine affinity of N-methyl-D-aspartate receptors. Mol Pharmacol. 2007;72:1535-1544.

26. Erreger K, Traynelis SF. Allosteric interaction between zinc and glutamate binding domains on NR2A causes desensitization of NMDA receptors. J Physiol. 2005;569:381-393.

27. Kloda A, Clements JD, Lewis RJ, Adams DJ. Adenosine triphosphate acts as both a competitive antagonist and a positive allosteric modulator at recombinant N-methyl-D-aspartate receptors. Mol Pharmacol. 2004;65:1386-1396.

28. Collingridge G. Synaptic plasticity. The role of NMDA receptors in learning and memory. Nature. 1987;330:604-605.

29. Grover LM, Kim E, Cooke JD, Holmes WR. LTP in hippocampal area CA1 is induced by burst stimulation over a broad frequency range centered around delta. Learn Mem. 2009;16:69-81.

30. Farin A, Marshall LF. Lessons from epidemiologic studies in clinical trials of traumatic brain injury. Acta Neurochir. 2004;Suppl 89:101-107.

31. Benveniste H, Drejer J, Schousboe A, Diemer NH. Elevation of the extracellular concentrations of glutamate and aspartate in rat hippocampus during transient cerebral ischemia monitored by intracerebral microdialysis. J Neurochem. 1984;43:1369-1374.

32. Ikonomidou C, Turski L. Why did NMDA receptor antagonists fail clinical trials for stroke and traumatic brain injury? Lancet Neurol. 2002;1:383-386.

33. Davis SM, et al. Selfotel in acute ischemic stroke : possible neurotoxic effects of an NMDA antagonist. Stroke. 2000;31:347-354.

34. Parsons CG, Stoffler A, Danysz W. Memantine: a NMDA receptor antagonist that improves memory by restoration of homeostasis in the glutamatergic system - too little activation is bad, too much is even worse. Neuropharmacology. 2007;53;699-723.

35. Lipton SA. Paradigm shift in neuroprotection by NMDA receptor blockade: memantine and beyond. Nat Rev Drug Discov. 2006;5:160-170.

36. Urakubo H, Honda M, Froemke RC, Kuroda S. Requirement of an allosteric kinetics of NMDA receptors for spike timing-dependent plasticity. J Neurosci. 2008;28:3310-3323.

37. Harrision NL, Simmonds MA. Quantitative studies on some antagonists of N-methyl-D-aspartate in slices of rat cerebral cortex. Br J Pharmacol. 1985;84:381-391 


\section{Supplementary materials}

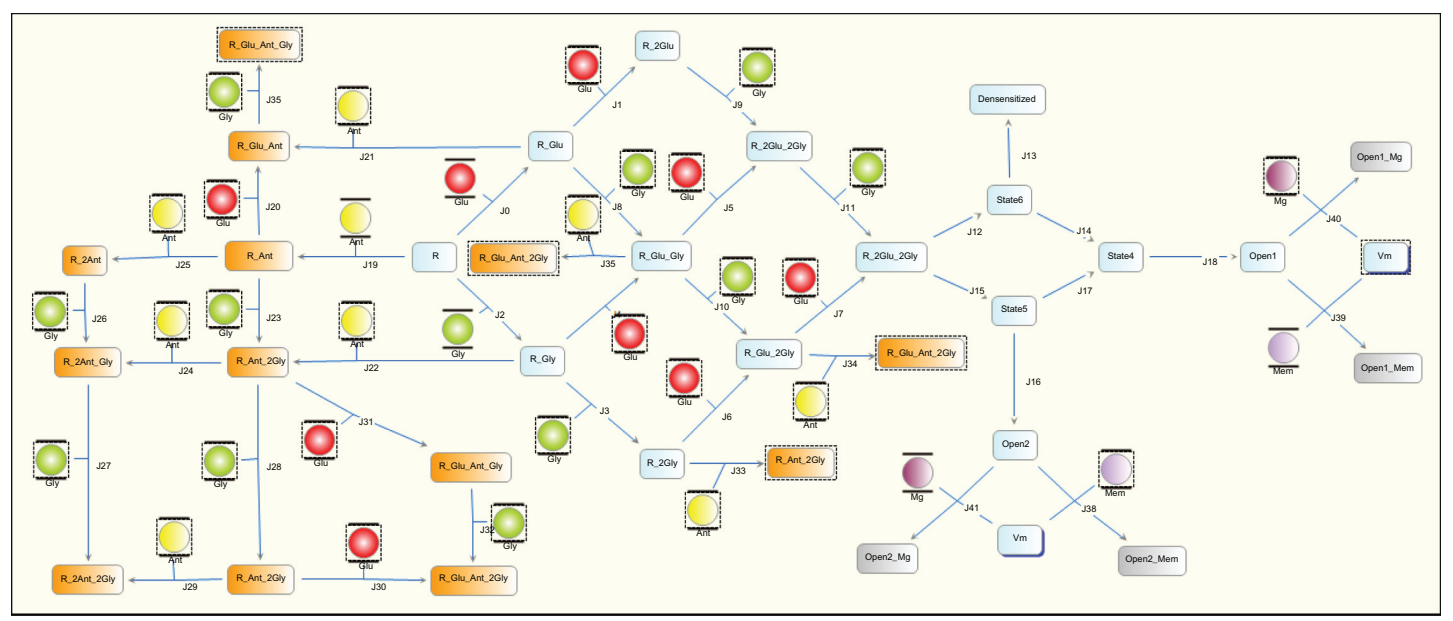

Supplementary figure I Kinetic scheme of the NMDA receptor with competitive and noncompetitive antagonists. Representation of the kinetic schema of the NMDAR from Schorge et al" with a competitive agonist, such as AP5 (orange boxes) and a noncompetitive antagonist, such as memantine (grey boxes) (adapted from Kotermanski et $\left.\mathrm{al}^{6}\right)$ implemented in a graphical user interface-based design tool for visual model development.

Notes: Each state binding a glutamate molecule in this new kinetic scheme also binds AP5 with association rate constant $\left(\mathrm{k}_{\text {onA }}\right)$ of $0.38 \mathrm{mM}^{-1} \cdot \mathrm{ms}^{-1}$ and dissociation rate constant $\left(\mathrm{k}_{\text {off }}\right)$ of $0.02 \mathrm{~ms}^{-1}$ for reactions labeled J 19, J2 I, J22, J24, J25, J29, J33, J34, and J35. We assumed that association rate constants for glycine and glutamate were not affected by AP5. Memantine binds to states Open I and Open2, which are now voltage-dependent (state $\mathrm{Vm}$ ) to generate states Open I_Mem and Open2_Mem, respectively. Mg ${ }^{2+}$ binds to states Open I and Open2 to generate states OpenI_Mg and Open2_Mg, respectively. The dissociation rate constant for memantine was set at $4.4 \mathrm{e}^{-4} \mathrm{~ms}^{-1}\left(\mathrm{k}_{\text {ofmem }}\right)$ and association $\left(\mathrm{k}_{\mathrm{onMem}}\right)$ was calculated as the ratio of $\mathrm{k}_{\text {ofmem }}$ and $\mathrm{Kd}$ with $\mathrm{Kd}=\left(0.8 \mathrm{e}^{-3} * \exp (\mathrm{Vm}+66) / 3 \mathrm{I} .6\right)$. Magnesium $\left(\mathrm{Mg}^{2+}\right)$ : association rate constant $\left(\mathrm{k}_{\text {onMg }}\right)$ was calculated with the following equation: $(426 * \exp [\mathrm{Vm} / 55]) /(\mathrm{I}+91.3 * \exp [\mathrm{Vm} / 21.0])$ and dissociation rate constant $\left(\mathrm{k}_{\text {offmg }}\right)$ with $61.8 \mathrm{e}^{-3} * \exp (-\mathrm{Vm} / 50.0)+4280 \mathrm{e}^{-3} * \exp (\mathrm{Vm} / 52.7)$, according to Kotermanski et al. ${ }^{6}$ NMDA-mediated current was calculated as $I_{\text {NMDA }}=n b_{N M D A} \times I_{0}$.

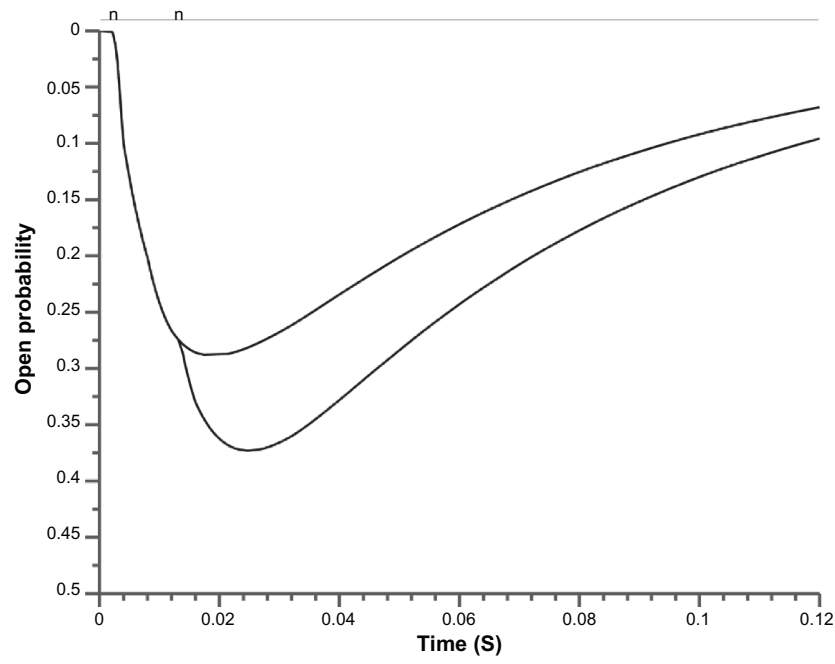

Supplementary figure 2 Paired pulse facilitation of NMDAR response.

Notes: Open probability of NMDAR in response to a single or a paired pulse application of I mM glutamate for I ms, with an interval between pulses of I0 ms, in the presence of $100 \mu \mathrm{M}$ glycine and in absence of $\mathrm{Mg}^{2+}$. The ration of peak open probabilities between the second and the first pulse was I.32.

Open Access Bioinformatics

\section{Publish your work in this journal}

Open Access Bioinformatics is an international, peer-reviewed, open access journal publishing original research, reports, reviews and commentaries on all areas of bioinformatics. The manuscript management system is completely online and includes a very quick and fair

peer-review system. Visit http://www.dovepress.com/testimonials.php to read real quotes from published authors. 